\title{
EDITOR'S FOCUS
}

Volume 85 No. 1 January 2019

\section{Early career investigator}

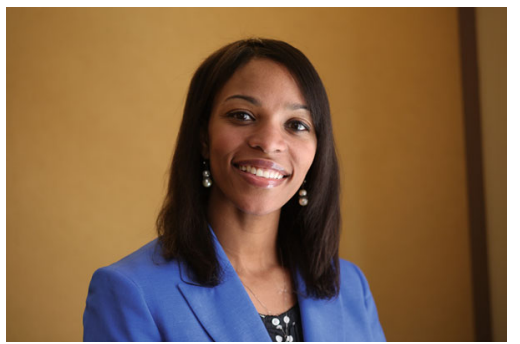

Congratulations to Stephanie LovinskyDesir, January's Early Career Investigator. Born in Mount Vernon, New York, she was inspired at an early age by her experience with asthma. Her training emphasized the social, environmental, and public policy factors that influence childhood disease. A walking tour of the South Bronx spurred her interest in environmental justice, an interest that still motivates her well-funded research. As an assistant professor in pediatric pulmonology at Columbia University, she advises trainees to develop networks of senior and peer mentors. In an article in this issue, she and colleagues demonstrate that neighborhood asthma prevalence modifies the relationship between air pollutants and urgent asthma care. See pages 6 and 36

\section{Genetic drivers of congenital} diaphragmatic hernia

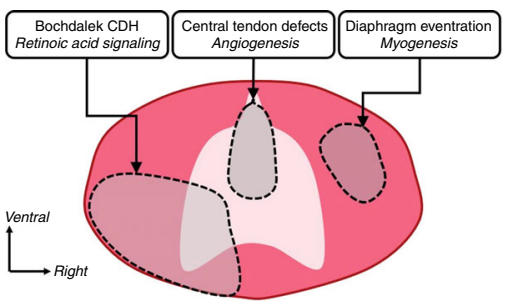

In a large-scale gene function analysis using gene ontology and 218 previously identified genes, Dalmer and Clugston identified significantly enriched biological pathways in the pathogenesis of congenital diaphragmatic hernia (CDH). Several unique genotype-phenotype relationships were found, highlighting the major genetic drivers of the different types of $\mathrm{CDH}$. See page 13
Waist-to-height ratio helps to identify children at increased risk of metabolic syndrome

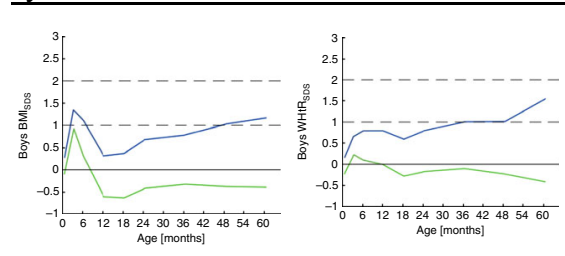

Lindholm et al. followed 1540 children from 0 to 5 years, recording both body mass index (BMI) and waist-to-height (WHtR). They found that BMl classification alone missed $50 \%$ of children with a higher WHtR who may be at risk for metabolic syndrome. See page $\mathbf{3 0}$

Platelets and plasma in donor blood contain high concentrations of lead

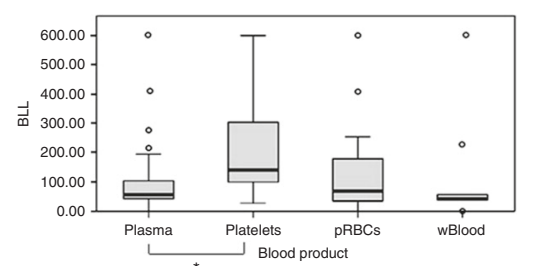

Aly et al. collected platelets, plasma, and packed red blood cells from Suez Canal University Hospital in Egypt. They found that $60 \%$ of samples had blood lead concentrations greater than $50 \mu \mathrm{g} / \mathrm{L}(5 \mu \mathrm{g} / \mathrm{dL})$. Surprisingly, the highest concentrations of lead were found in platelets. A related study conducted in Omaha, Nebraska, and a commentary on the issue of heavy metals in donor blood are presented in this issue. See pages 50, 4, and 7

Sex differences in brain structure in early life

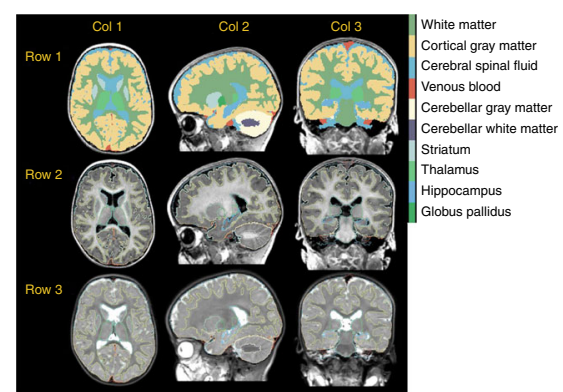

Benavides et al. obtained data from questionnaires and MRI images at 1 year corrected age for 33 infants born at differing gestational age. They found primary effects of sex on brain structure and sex-specific effects of gestational age that were significant in preterm males. See page 55

\section{Fish consumption during pregnancy and visual-tract development in offspring \\ BSIP SA/Alamy}

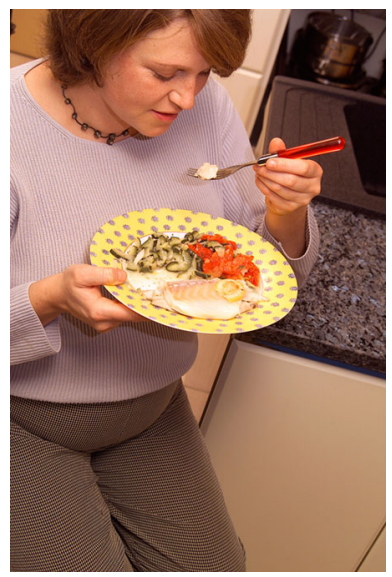

Normia et al. examined the association between diet in pregnancy and visual neurodevelopment. They found that the infants of women who consumed at least three fish meals a week in the last trimester of pregnancy performed better on tests of visual-tract function. See page 72

Neurosteroid replacement improves behavioral outcomes in preterm guinea pigs

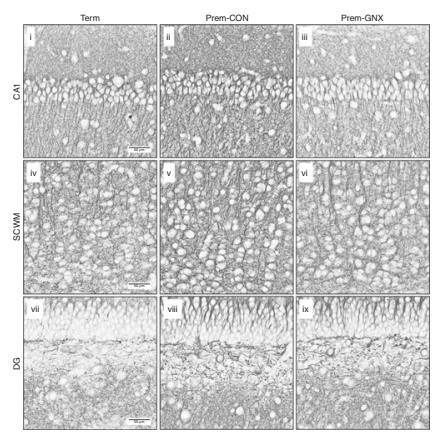

Shaw et al. administered ganaxolone to guinea pigs that had been delivered prematurely. Hyperactive behavior and deficits in myelin basic protein immunostaining were significantly ameliorated. Unfortunately, the treated pups had a high mortality rate, indicating the need for dose-response studies. See page 86 